\section{Correspondence on 'Systemic evaluation of the relationship between psoriasis, psoriatic arthritis and osteoporosis: observational and Mendelian randomisation study'}

We read with great interest the published paper by Xia et $a l^{1}$ which provided an in-depth analysis regarding the relationship between psoriasis, psoriatic arthritis (PsA) and osteoporosis. By comprehensively analysing the datasets from three Genome-Wide Association Studies and UK Biobank, the authors concluded that the association between PsA and estimated bone mineral density (eBMD)/osteoporosis/fracture was not genetically determined but secondary (eg, treatment with methotrexate or ciclosporin). Although the conclusion was drawn based on very stringent confounders controlling, there are a few points in this study that are worth mentioning.

First, typically, many background characteristics should be controlled in an observational study, especially with large datasets. In association analysis part, only seven confounders (ie, age, height, weight, smoking, drinking, regular physical activity and medication treatments) were controlled. It is well established that psoriasis/PsA is a systemic inflammatory disorder that is associated with several comorbidities, for example, cardiovascular disease $^{2} 3$ and metabolic syndrome (namely, diabetes mellitus, obesity, hypertension and dyslipidaemia). ${ }^{45}$ These comorbidities may also have residual confounding effect on the association between psoriasis, PsA and osteoporosis.

Second, we noted that there were a total of 432513 psoriasis/controls and $428455 \mathrm{PsA} /$ controls in UK data-1 dataset, the baseline imbalance presumably existed between psoriasis/PsA cases and controls. Although this is not a concern to consider running multivariable linear/logistic regression, it is convincing to clarify and eliminate the imbalance to testify and strengthen the regression. It is preferable to use propensity score methods for confounder controlling, ${ }^{6}$ though it will cause the reduction of sample size, it has been widely accepted and used in other observational studies. $^{78}$

Third, the information about medication treatment (mainly refers to methotrexate and ciclosporin in the text) should be described more detailed, especially the ciclosporin. Because ciclosporin is recommended for the management of skin psoriasis, ${ }^{9}$ however, it is not put forward in the EULAR recommendations for the management of PsA, ${ }^{10}$ because lack of convincing efficacy. ${ }^{11} 12$ More importantly, disease activity is another issue that should be addressed when interpreting the relationship between psoriasis, PsA and osteoporosis. Evidence suggests that there is a high prevalence of osteoporosis in patients with spondyloarthritis, ${ }^{13}$ and patients with high disease severity are prone to suffering from more comorbiditites, including osteoporosis. ${ }^{14}$ Additionally, disease activity is an important factor affecting medication because PsA cases with high disease activity trend to take more methotrexate and/or ciclosporin. Therefore, high disease activity seems to be a contributor for taking methotrexate or ciclosporin, and then for osteoporosis, which exactly explain that PsA cases, rather than psoriasis, was found to contribute to lower eBMD in this study.

Last but not least, in Mendelian randomisation approach part, multiple sensitivity methods were used to explore horizontal pleiotropy, however, linkage disequilibrium, other key issue of Mendelian randomisation analysis, should be taken into consideration to avoid false positive of causal effects. New evidence showed that linkage disequilibrium is widespread in naïve phenome-wide association studies of proteins, and nearly $31.5 \%$ associations, which being supported by evidence from Mendelian randomisation, however, were not supported by results of colocalisation analyses. ${ }^{15}$

\section{Ran Cui ๑ , Qiang Tong, Zhi-Yong Chen, Miao Chen, Sheng-Ming Dai}

Department of Rheumatology and Immunology, Shanghai Jiao Tong University Affiliated Sixth People's Hospital, Shanghai Jiao Tong University, Shanghai, China

Correspondence to Professor Sheng-Ming Dai, Department of Rheumatology and Immunology, Shanghai Jiao Tong University Affiliated Sixth People's Hospital, Shanghai Jiao Tong University, Shanghai 200233, China; shengmingdai@163. com

Contributors RC and S-MD conceived the manuscript. RC drafted the manuscript. The other authors reviewed and commented on the manuscript. All authors approved the final version of the manuscript.

Funding The authors have not declared a specific grant for this research from any funding agency in the public, commercial or not-for-profit sectors.

Competing interests None declared.

Patient and public involvement Patients and/or the public were not involved in the design, or conduct, or reporting, or dissemination plans of this research.

Patient consent for publication Not required.

Provenance and peer review Not commissioned; internally peer reviewed.

(c) Author(s) (or their employer(s)) 2020. No commercial re-use. See rights and permissions. Published by BMJ.

$$
\text { Check for updates }
$$

To cite Cui R, Tong Q, Chen Z-Y, et al. Ann Rheum Dis Epub ahead of print: [please include Day Month Year]. doi:10.1136/annrheumdis-2020-219173

Received 23 September 2020

Accepted 24 September 2020

\section{CLinked}

- http://dx.doi.org/10.1136/annrheumdis-2020-219183

Ann Rheum Dis 2020;0:1-2. doi:10.1136/annrheumdis-2020-219173

ORCID iD

Ran Cui http://orcid.org/0000-0003-4923-5882

\section{REFERENCES}

1 Xia J, Xie S-Y, Liu K-Q, et al. Systemic evaluation of the relationship between psoriasis, psoriatic arthritis and osteoporosis: observational and Mendelian randomisation study. Ann Rheum Dis 2020. doi:10.1136/annrheumdis-2020-217892. [Epub ahead of print: 31 Jul 2020].

2 Armstrong AW, Harskamp CT, Ledo L, et al. Coronary artery disease in patients with psoriasis referred for coronary angiography. Am J Cardiol 2012;109:976-80.

3 Dey AK, Joshi AA, Chaturvedi A, et al. Association between skin and aortic vascular inflammation in patients with psoriasis: a case-cohort study using positron emission tomography/computed tomography. JAMA Cardiol 2017;2:1013-8.

4 Caso F, Chimenti MS, Navarini L, et al. Metabolic syndrome and psoriatic arthritis: considerations for the clinician. Expert Rev Clin Immunol 2020;16:409-20.

5 Mok CC, Ko GTC, Ho LY, et al. Prevalence of atherosclerotic risk factors and the metabolic syndrome in patients with chronic inflammatory arthritis. Arthritis Care Res 2011;63:195-202

6 D'Agostino RB. Propensity score methods for bias reduction in the comparison of a treatment to a non-randomized control group. Stat Med 1998;17:2265-81.

7 Stukel TA, Fisher ES, Wennberg DE, et al. Analysis of observational studies in the presence of treatment selection bias: effects of invasive cardiac management on AMI survival using propensity score and instrumental variable methods. JAMA 2007;297:278-85.

8 Yu T-M, Chuang Y-W, Yu M-C, et al. Risk of cancer in patients with polycystic kidney disease: a propensity-score matched analysis of a nationwide, population-based cohort study. Lancet Oncol 2016;17:1419-25.

9 Stiff KM, Glines KR, Porter CL, et al. Current pharmacological treatment guidelines for psoriasis and psoriatic arthritis. Expert Rev Clin Pharmacol 2018;11:1209-18.

10 Gossec L, Baraliakos X, Kerschbaumer A, et al. EULAR recommendations for the management of psoriatic arthritis with pharmacological therapies: 2019 update. Ann Rheum Dis 2020;79:700-12. 
11 Fraser AD, van Kuijk AWR, Westhovens $R$, et al. A randomised, double blind, placebo controlled, multicentre trial of combination therapy with methotrexate plus ciclosporin in patients with active psoriatic arthritis. Ann Rheum Dis 2005:64:859-64.

12 Kerschbaumer A, Smolen JS, Dougados M, et al. Pharmacological treatment of psoriatic arthritis: a systematic literature research for the 2019 update of the EULAR recommendations for the management of psoriatic arthritis. Ann Rheum Dis 2020;79:778-86.
13 Moltó A, Etcheto A, van der Heijde D, et al. Prevalence of comorbidities and evaluation of their screening in spondyloarthritis: results of the International cross-sectional ASAS-COMOSPA study. Ann Rheum Dis 2016;75:1016-23.

14 Zhao SS, Radner H, Siebert S, et al. Comorbidity burden in axial spondyloarthritis: a cluster analysis. Rheumatology 2019;58:1746-54.

15 Zheng J, Haberland V, Baird D, et al. Phenome-wide Mendelian randomization mapping the influence of the plasma proteome on complex diseases. Nat Genet 2020. doi:10.1038/s41588-020-0682-6. [Epub ahead of print: 07 Sep 2020]. 